\title{
Pengaruh Kadar Semen Terhadap Stabilitas Tanah Lempung Ditinjau Dari Kuat Geser Tanah
}

\author{
Wulan Novita Purwati ${ }^{1}$, Rokhman $^{2}$, Hendrik Pristianto $^{3}$ \\ 1,2,3 Progam Studi Teknik Sipil Universitas Muhammadiyah Sorong
}

\begin{abstract}
Abstrak
Stabilitas tanah merupakan salah satu usaha untuk meningkatkan kapasitas daya dukung tanah. Tanah lempung plastisitas tinggi berpotensi menjadi tanah yang bermasalah karena mempunyai kekuatan rendah dan penurunan yang tinggi. Salah satu metode untuk meningkatkan daya dukung adalah stabilisasi tanah lempung salah satunya menggunakan Portland Cement Type I. Penelitian ini diharapkan untuk mengetahui seberapa besar pengaruh perubahan semen terhadap nilai kuat geser tanah. Dalam penelitian ini tanah yang digunakan berasal dari Jalan Makam Kelurahan Malason, Distrik Aimas, Kabupaten Sorong. Pengujian tanah ini terdiri dari pengujian fisik dan mekanis, pengujian yang utama dilakukan adalah pengujian Direct Shear Test (Uji Kuat Geser Langsung) yang dilakukan di Laboratorium Mekanika Tanah Fakultas Teknik Universitas Muhammadiyah Sorong dan berpedoman pada SNI dengan variasi campuran semen sebesar 2\%, 4\%, 6\%, $8 \%$ dan 10\%. Dari hasil penelitian didapatkan bahwa semakin besar variasi semen maka tegangan geser, kohesi dan sudut geser semakin meningkat. Nilai tegangan geser, kohesi dan sudut geser yang tertinggi pada penambahan bahan stabilitas sebesar $10 \%$ dengan waktu pemeraman 3 hari dengan nilai tegangan geser $0,541 \mathrm{~kg} / \mathrm{cm}^{2}$ kohesi sebesar $0,172 \mathrm{Kg} / \mathrm{cm}^{2}$ dan sudut geser sebesar $42,62^{\circ}$. Hal ini menunjukan bahwa semen dapat dijadikan bahan stabilisasi untuk meningkatkan kekuatan dan daya dukung tanah lempung ditinjau dari peningkatan nilai tegangan geser, kohesi tanah dan sudut geser yang dihasilkan.
\end{abstract}

Kata kunci : Direct Shear Test (DST), Kuat Geser, Semen, Stabilitas Tanah, Tanah Lempung.

\section{PENDAHULUAN}

Kabupaten Sorong adalah salah satu kabupaten di papua barat yang saat ini berada pada masa pembangunan. Dengan semakin banyaknya pembangunan di kabupaten sorong maka pembangunan jalan merupakan salah satu hal yang selalu beriringan dengan perkembangan kota dan pemerataan pembangunan antar daerah, karna jalan merupakan fasilitas penting bagi manusia agar dapat mencapai suatu daerah yang ingin di capai.

Saat ini banyak jalan yang mengalami kerusakan di Jalan Makam Kelurahan Malason, Distrik Aimas, Kabupaten Sorong. Kondisi jalan di daerah ini mengalami kerusakan antara lain jalan yang berlubang, bergelombang menjadi masalah utama di daerah ini.

Klasifikasi tanah di Kabupaten Sorong terdiri dari tekstur halus, sedang, kasar, dan gambut. Mayoritas tanah di wilayah Kabupaten Sorong mayoritas bertekstur halus (Irwanto, 2016). Secara umum tanah bertekstur halus adalah tanah lempung. Tanah lempung adalah suatu jenis tanah kohesif yang mempunyai sifat sangat kurang menguntungkan dalam kostruksi teknik sipil yaitu kuat geser rendah dan kompresibilitasnya yang besar. Kuat geser yang rendah dapat mengakibatkan terbatasnya beban yang dapat berkerja di atasnya sedangkan kompresibilitasnya yang besar mengakibatkan terjadinya penurunan setelah bangunan selesai.

Dengan permasalahan yang terjadi dilapangan maka tanah di Jalan Makam Kelurahan, Malason Distrik Aimas, Kabupaten Sorong perlu diadakan perbaikan tanah dengan cara menstabilisasi tanah secara kimawi menggunakan semen sebagai bahan stabilisasinya. Semen merupakan stabilizing agent yang baik sekali, karena kemampuannya mengeras dan mengikat butir - butir agregat.

\section{Tujuan Penelitian}

1) Untuk mengidentifikasi karakteristik tanah asli Jalan Makam Kelurahan Malason Distrik Aimas Kabupaten Sorong

2) Untuk menganalisis seberapa besar pengaruh semen terhadap nilai kuat geser tanah

\section{METODE PENELITIAN}

Metode yang digunakan metode eksperimen yang dilakukan dengan mengadakan kegiatan pengujian untuk mendapatkan data. Data tersebut kemudian di olah untuk mendapatkan perbandingan dengan syarat-syarat yang ada, kemudian menganalisa data tersebut berdasarkan teori yang berkaitan dengan kondisi dari sampel tanah tersebut.

Lokasi pengambilan sampel tanah terletak di Jalan Makam, Kelurahan Malason, Distrik Aimas, Kabupaten Sorong.koordinat dari google earth. 
Sampel tanah yang diambil adalah sampel tanah terganggu(distributed soil) dan yang menjadi bahan pertinjauan penelitian disini adalahakan dilakukan pengujian dengan kadar pencampuran semen yang berbeda untuk mengetahui daya dukung tanah tersebut.

Dalam pengumpulan data penelitian ini dilakukan di Laboratorium Mekanika Tanah, Jurusan Teknik Sipil, Fakultas Teknik, Universitas Muhammadiyah Sorong. Waktu penelitian dilakukan dari bulan Mei sampai Agustus.

\section{Alat dan Bahan}

a) Bahan yang digunakan dalam penelitian di laboratorium adalah :

1) Tanah lempung yang di ambil sampel tanahnya di daerah Jalan Makam Kelurahan Malason Distrik Aimas Kabupaten Sorong.

2) Semen yang digunakan sebagai bahan tambah stabilisasi adalah semen jenis PCC (portland composite cement).

b) Alat yang digunakan dalam penelitian di laboratorium :

1) Alat Pengujian Kadar Air

2) Alat Pengujian Atterberg Limit

a) Alat pengujian batas cair

b) Alat pengujian batas plastis

3) Alat Pengujian Berat Jenis (Spesific Gravity)

4) Alat Pengujian Analisa Butir Tanah

a) Alat Pengujian Analisa Butiran Hidrometer

b) Alat Pengujian Analisa Saringan

5) Alat Pengujian Pemadatan (Compaction)

6) Alat Pengujian Direct Shear Test

\section{Teknik Pengumpulan Data}

Data-data yang digunakan dalam penelitian ini adalah sebagai berikut :

\section{Data Primer}

Pengumpulan data primer merupakan pengumpulan data yang dilakukan oleh peneliti yang diperoleh secara langsung dilokasi penelitian. Data primer ini berupa :

1) Pengujian Berat Jenis Tanah (Specific Gravity).

2) Pengujian Kadar Air Tanah.

3) Pengujian Batas Atterberg, meliputi : Pengujian Batas Cair (Liquid Limit) dan Batas Plastis (Plastic Limit).

4) Pengujian Analisa Ukuran Butir Tanah Dengan Hidrometer.

5) Pengujian Analisa Saringan.

6) Pengujian Pemadatan (Compaction)

7) Pengujian Kuat Geser Langsung.

\section{Data Sekunder}

Pengumpulan data sekunder merupakan pengumpulan data secara tidak langsung dari sumber atau objek. Pengumpulan data sekunder, yaitu : (a)Studi Pustaka, Data - data sekunder itu diperoleh tulisan seperti buku-buku teori, laporan, artikel, dan penelitian terdahulu yang berasal dari instansi terkait maupun hasil kajian literatur. (b)Media elektronik seperti website.

\section{Metode Pencampuran Sampel Tanah Dengan Semen}

Metode pencampuran untuk masing masing presentasi semen adalah : (1)Tanah sampel diambil dari lokasi pengambilan terlebih dulu di keringkan secara alami dengan cara dihampar di bawah sinar matahari. (2)Tanah yang telah kering diayak menggunakan saringan No. 4 (4,75 mm). (3)Tanah yang diayak dan di timbang sesuai dengan yang dibutuhkan. (4)Semen yang dicampur dengan sampel tanah yang telah di tumbuk dan lolos saringan No.4 $(4,75 \mathrm{~mm})$ dengan presentasi semen $2 \%, 4 \%, 6 \%, 8 \%$ dan $10 \%$ dari berat sampel tanah. (5)Pencampuran dilakukan dengan cara menimbang sampel tanah dan semen sesuai kadar masingmasing pada tiap campuran kemudian mencampurkan dua bahan tersebut kemudian di padatkan dengan cara pemadatan (compaction). (6)Pembuatan masing-masing benda uji untuk pemadatan dengan kadar air optimum diambil dari hasil pengujian proctor test, berat tanah tiap mold 2 , berat mold, luas mold, tinggi jatuh penumbuk dengan 5 lapisan. (7)Sampel tanah dari mold dikeluarkan dengan ekstruder. Setelah sampel dikeluarkan dan dilakukan koreksi terhadap tinggi sampel dengan cara memotong sampel dengan wire saw. (8) Setelah itu dibuat pencampuran benda uji ditimbang tanah dan campuran sebanyak $1 \mathrm{~kg}$. Tanah dan campuran yang telah di timbang di tambah air dari sesuai kadar air optimum yang di dapat dari pengujian pemadatan, dan dari pengujian pemadatan (compaction) itu di dapat nilai berat isi basah, lalu dari nilai itu dikalikan dengan volume ring. Dan dari perhitungan tersebut di dapat berat isi tanah yang harus di cetak didalam ring. (9)Semua tanah yang di timbang harus masuk di dalam ring, setelah dipadatkan tanah di keluarkan dari ring. Kemudian benda uji tersebut di peram selama 3×24 jam, dalam proses pemeraman di usahakan benda uji di tutup sehingga tidak ada udara yang masuk ke dalam benda uji. Masing-masing benda uji dibuat sebanyak 3 buah untuk pengujian geser langsung. 
Tabel 1. Kadar Pencampuran Tanah Lempung Dengan Semen

\begin{tabular}{ccc}
\hline NO & JENIS PENGUJIAN & JUMLAH SAMPEL \\
\hline 1 & Tanah Asli & 3 Buah \\
& Tanah Asli + Semen & \\
& $2 \%$ Semen & 3 Buah \\
2 & $4 \%$ Semen & 3 Buah \\
& $6 \%$ Semen & 3 Buah \\
& $8 \%$ Semen & 3 Buah \\
& $10 \%$ Semen & 3 Buah \\
\hline & Jumlah Sampel & 18 Buah \\
\hline
\end{tabular}

(Sumber : Kadar Pencampuran Tanah Dengan Semen)

Tabel 2. Perbandingan campuran tanah lempung + semen untuk uji geser langsung

\begin{tabular}{|c|c|c|c|c|c|}
\hline \multirow{2}{*}{$\mathrm{N}_{0}$} & \multicolumn{2}{|c|}{ Tanah Lempung } & \multicolumn{2}{|c|}{ Semen } & \multirow{2}{*}{$\begin{array}{c}\text { Berat } \\
\text { Campuran } \\
\text { Berat }(\mathrm{kg})\end{array}$} \\
\hline & Presentase (\%) & $\begin{array}{l}\text { Berat } \\
(\mathrm{kg})\end{array}$ & Presentase (\%) & $\begin{array}{l}\text { Berat } \\
(\mathrm{kg})\end{array}$ & \\
\hline 1 & $99 \%$ & 0.98 & $2 \%$ & 0.02 & $1 \mathrm{~kg}$ \\
\hline 2 & $96 \%$ & 0.96 & $4 \%$ & 0.04 & $1 \mathrm{~kg}$ \\
\hline 3 & $94 \%$ & 0.94 & $6 \%$ & 0.06 & $1 \mathrm{~kg}$ \\
\hline 4 & $92 \%$ & 0.92 & $8 \%$ & 0.08 & $1 \mathrm{~kg}$ \\
\hline 5 & $90 \%$ & 0.9 & $10 \%$ & 0.1 & $1 \mathrm{~kg}$ \\
\hline
\end{tabular}

(Sumber : Perbandingan Pencampuran Tanah Dan Semen, 2018)

\section{Flowchart Penelitian}

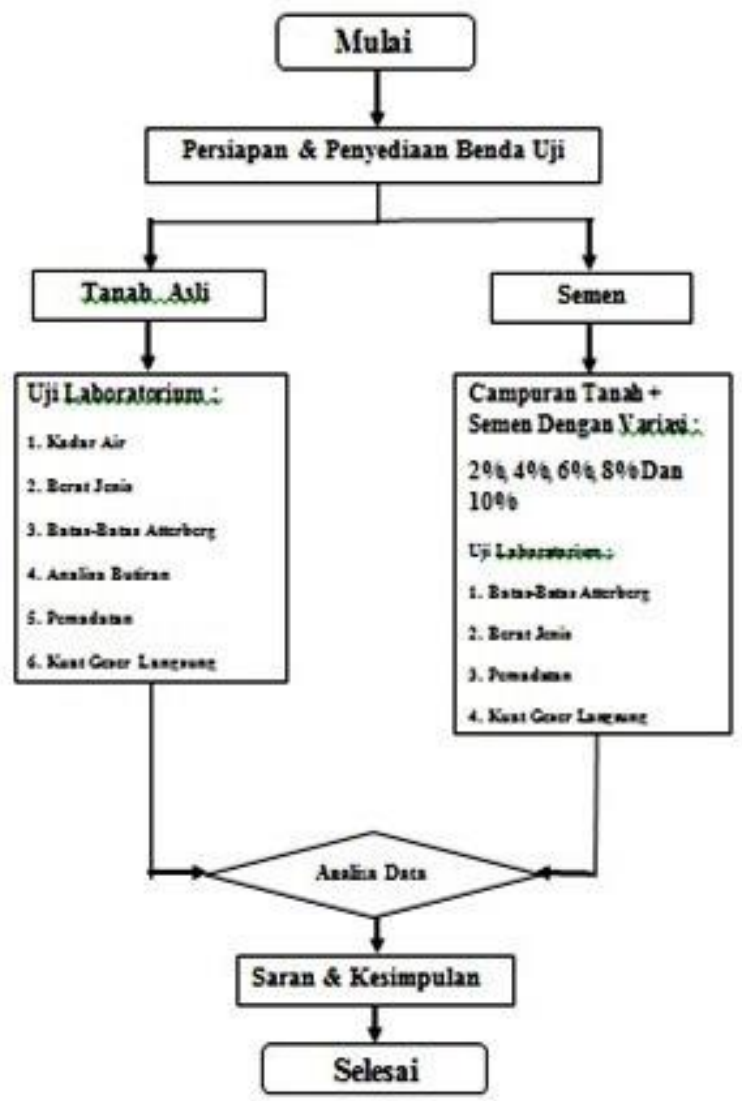

Gambar 1. Diagram alir penelitian

\section{HASIL PENELITIAN DAN PEMBAHASAN Karakteristik Tanah Asli}

Berdasarkan data hasil pengujian dapat diklasifikasikan sifat tanah berdasarkan atas beberapa sistem yang ada yaitu (1) Sistem Klasifikasi USCS (2) Sistem Klasifikasi AASHTO

\section{Sistem Klasifikasi $U S C S$}

Sistem klasifikasi ini paling banyak diaplikasikan pada pengujian tanah. Sistem klasifikasi USCS merupakan sistem pengelompokan berbasis hasil percobaan laboratorium. Adapun hasil dari pengujian laboratorium menunjukan data propertis tanah yang di peroleh adalah : (1)Tanah yang lolos saringan no. $200=78,50 \%$ (2)Batas cair (LL) $=$ $64,52 \%$ (3)Indeks plastisitas (IP) $=37,23 \%$

Dari data propertis tanah yang diperoleh di atas maka dapat disimpulkan beberapa hal, yaitu : (a)Berdasarkan nilai presentase lolos saringan no. 200 tanah lempung diatas, presentase tersebut lebih besar dari $50 \%$, maka berdasarkan tabel klasifikasi USCS tanah ini secara umum di kategorikan sebagai tanah berbutir halus. (b)Dari tabel sistem kualifikasi USCS untuk data batas cair dan indeks plastisitas diplotkan pada diagram plastisitas sehingga didapatkan identifikasi tanah yang lebih spesifik.

\section{USCS}

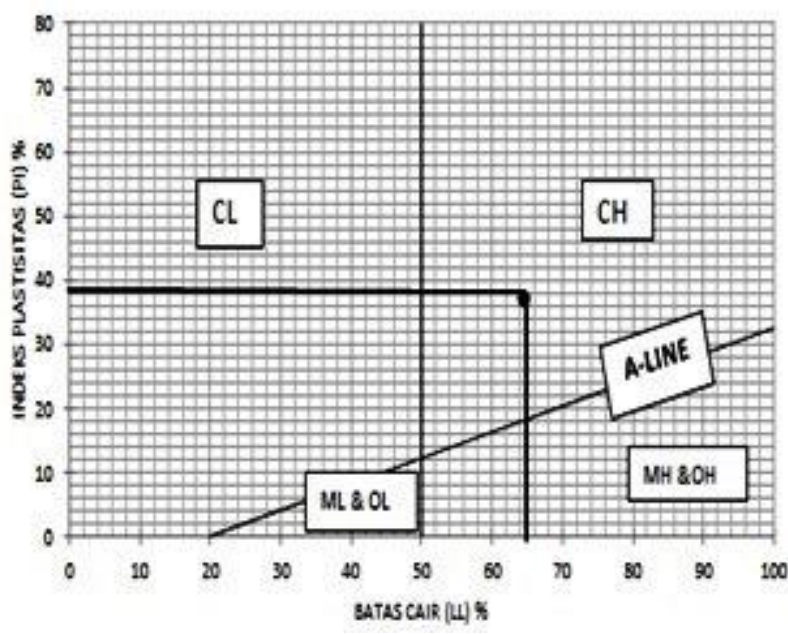

Gambar 2. Grafik hubungan indeks plastisitas dan batas cair USCS

Dengan merujuk pada gambar di atas maka tanah berbutir halus di Jalan Makam Kelurahan Malason Distrik Aimas Kabupaten Sorong termasuk kedalam kelompok $\mathrm{CH}$ yaitu tanah lempung organic dengan plastisitas tinggi, lempung gemuk dengan nilai indeks plastisitas 37,23\% (plastisitas tinggi). Untuk lebih jelasnya dapat dilihat pada tabel 2 . 


\section{Sistem Klasifikasi AASHTO}

Berdasarkan pada tabel klasifikasi tanah AASHTO dan properties tanah, dimana presentase lolos saringan no.200 lebih dari $36 \%$, sehingga dapat disimpulkan secara umum tanah masuk dalam kelompok lanau - lempung. Dengan diketehuinya nilai batas cair (LL) lebih besar dari $41 \%$, dan nilai indeks plastisitas (PI) lebih besar dari $11 \%$ dan nilai batas plastis (PL) lebih dari 30\% maka tanah termasuk golongan A-7-6.

Untuk pengelompokan yang lebih detail maka dapat dilihat pada gambar 10 .

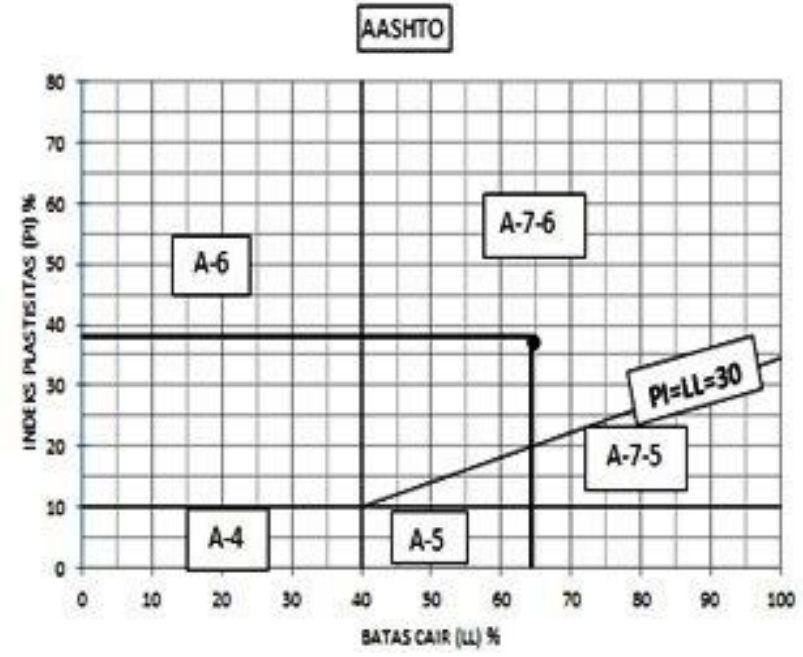

Gambar 3. Grafik hubungan indeks plastisitas dan batas cair AASHTO

Berdasarkan gambar di atas maka tanah lempung yang berasal dari jalan makam kelurahan malason distrik aimas kabupaten sorong dapat dikategorikan kedalam kelompok tanah lempung A-7-6. Untuk lebih jelasnya dapat dilihat pada tabel 1 .

\section{Hasil Pengujian Tanah Asli + Variasi Kadar Semen}

Setelah pengujian tanah asli dilakukan, maka tahap selanjutnya adalah pengujian tanah campuran dalam hal ini adalah tanah asli yang dicampur dengan kadar variasi semen sebesar 2\%, 4\%, 6\%, $8 \%$ dan $10 \%$. Pengujian tanah campuran meliputi batas-batas atterberg, berat jenis (GS), pemadatan (compaction) dan kuat geser langsung (direct shear test) ini dilakukan untuk mengetahui seberapa besar pengaruh penambahan kadar semen terhadap tanah asli.

\section{Pengujian Berat Jenis (GS)}

Tabel 3. Hasil pengujian berat jenis tanah dengan campuran semen

\begin{tabular}{ccc}
\hline No & Kadar Semen (\%) & $\begin{array}{c}\text { Berat Jenis } \\
\text { Tanah }\left(\mathbf{g r} / \mathbf{c m}^{3}\right)\end{array}$ \\
\hline 1 & 0 (Tanah Asli) & 2.4 \\
2 & 2 & 2.55 \\
3 & 4 & 2.56 \\
4 & 6 & 2.60 \\
5 & 8 & 2.62 \\
6 & 10 & 2.63 \\
\hline
\end{tabular}

(Sumber : Hasil Perhitungan, 2018)

\section{Berat Jenis}

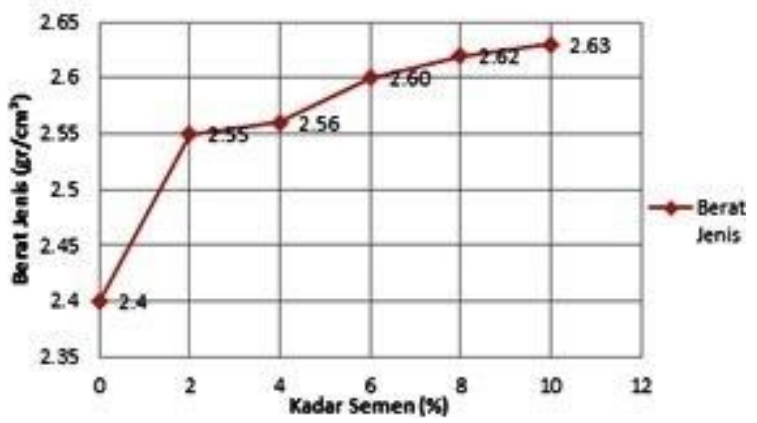

Gambar 4. Grafik Pengaruh Kadar Semen

Terhadap Nilai Berat Jenis (GS)

Dari tabel hasil pengujian dan gambar diatas dapat dilihat seiring bertambahnya kadar campuran semen, tanah lempung mengalami kenaikan berat jenis campuran. Dapat kita lihat berat jenis sebelum penambahan semen di dapat $2,40 \mathrm{gr} / \mathrm{cm}^{3}$ dan penambahan $10 \%$ semen berat jenis meningkat menjadi 2,63 gr/ $\mathrm{cm}^{3}$. Bertambahnya ukuran butiran ini akan mengakibatkan makropori dan mikropori yang ada pada tanah lempung meningkat seiring dengan bertambahnya semen. Oleh karena itu penembahan semen pada tanah lempung akan menyebabkan air sulit masuk ke mikropori dan mikropori lempung, sehingga penambahan semen akan menyebabkan berat jenis tanah lempung meningkat.

\section{Pengujian Atterberg Limit}

Tabel 4. Hasil pengujian atterberg limit dengan campuran semen

\begin{tabular}{ccccc|}
\hline No & $\begin{array}{c}\text { Kadar Semen } \\
(\%)\end{array}$ & $\begin{array}{c}\text { LL } \\
(\%)\end{array}$ & $\begin{array}{c}\text { PL } \\
(\%)\end{array}$ & $\begin{array}{c}\text { IP } \\
(\%)\end{array}$ \\
\hline 1 & 0 (Tanah Asli) & 64.52 & 27.29 & 37.23 \\
2 & 2 & 60.83 & 30.37 & 30.47 \\
3 & 4 & 58.76 & 32.24 & 26.52 \\
4 & 6 & 57.61 & 33.18 & 24.43 \\
5 & 8 & 55.97 & 34.22 & 21.75 \\
6 & 10 & 54.86 & 35.15 & 19.71 \\
\hline
\end{tabular}

(Sumber : Hasil Perhitungan, 2018) 


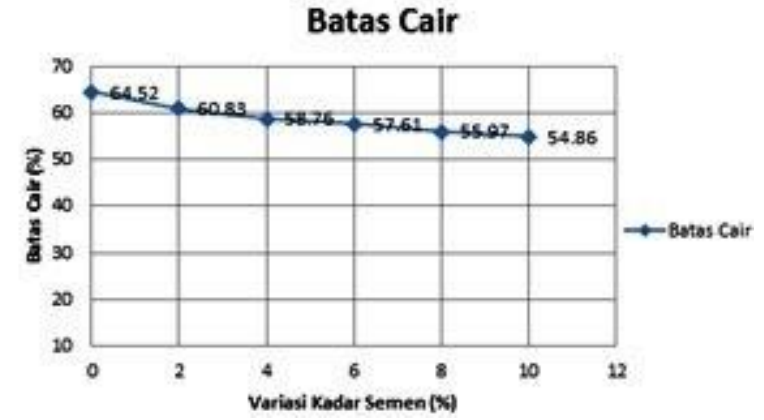

Gambar 5. Grafik Pengaruh Kadar Semen Terhadap Nilai Batas Cair

Dari gambar grafik diatas batas cair mengalami penurunan pada setiap penambahan kadar semen. Hal ini disebabkan semen mengisi rongga pori tanah yang pada kondisi tanah asli, rongga pori diisi oleh air dan udara. Akibat adanya semen dalam rongga pori tanah presentasi air yang dikandung tanah menjadi berkurang.

\section{Batas Plastis}

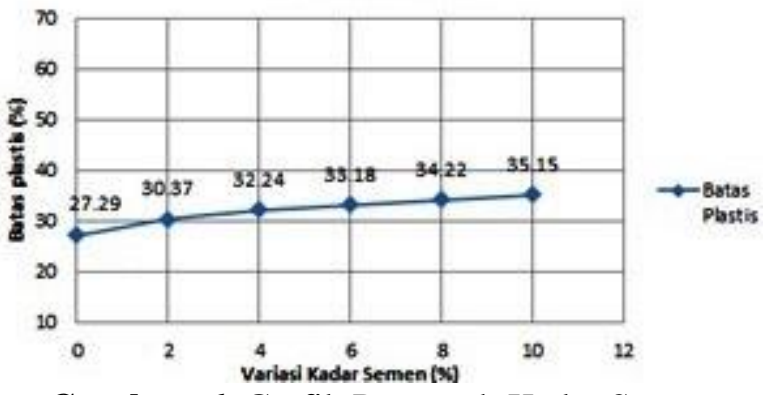

Gambar 6. Grafik Pengaruh Kadar Semen

Terhadap Nilai Batas Plastis

Dari gambar diatas terlihat bahwa seiring dengan bertambahnya semen maka nilai batas plastis meningkat, ini berarti bahwa semakin banyaknya kandungan semen maka akan semakin banyak pula air yang dibutuhkan untuk merubah dari kondisi semi padat menjadi kondisi plastis. Dalam konteks ini berarti bahwa tanah lempung dengan penambahan semen membuat tanah menjadi lebih stabil.

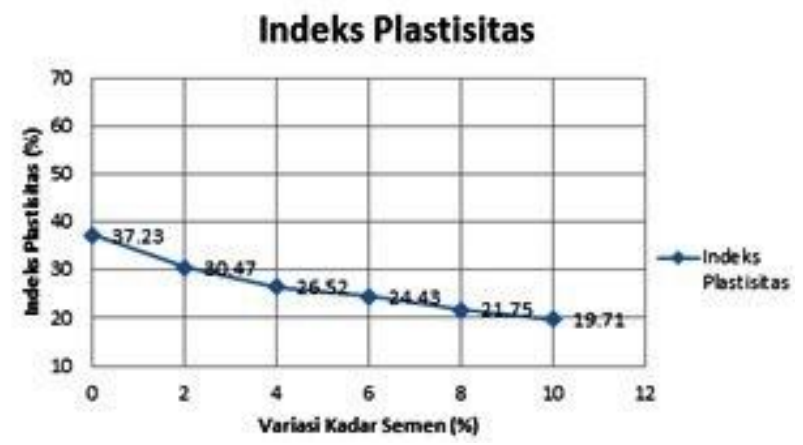

Gambar 7. Grafik Pengaruh Kadar Semen Terhadap Nilai Indeks Plastisitas

Dari gambar grafik diatas diketahui bahwa semakin banyaknya semen maka akan semakin kecil rentang indek plastisitas dengan kata lain semakin sedikit kemungkinan berada pada kondisi plastis. Hal ini dapat diartikan penambahan semen dapat menjadikan tanah lebih stabil dan penambahan semen pada tanah lempung maka akan mengendalikan sifat plastis dari tanah lempung tersebut sehingga tanah menjadi lebih stabil. Selain itu unsur kimia dari semen disinyalir bercampur dengan air membentuk pasta yang mengikat partikel lempung dan mampu menutupi pori-pori tanah membuat air sulit menyerap dalam campuran tanah semen sehingga mampu menurunkan sifat plastisnya.

\section{Pengujian Pemadatan (Compaction)}

Tabel 5. Hasil pengujian pemadatan (compaction) dengan campuran semen

\begin{tabular}{cccc}
\hline No. & $\begin{array}{c}\text { Variasi } \\
\text { Campuran Semen } \\
(\%)\end{array}$ & $\begin{array}{c}\text { Berat isi } \\
\text { Basah }(\mathrm{gr})\end{array}$ & $\begin{array}{c}\text { Berat Isi Kering } \\
\left(\mathrm{g} / \mathrm{cm}^{3}\right)\end{array}$ \\
\hline 1 & 0(Tanah Asli) & 1.817 & 1.583 \\
2 & 2 & 1.996 & 1.654 \\
3 & 4 & 2.000 & 1.659 \\
4 & 6 & 2.014 & 1.664 \\
5 & 8 & 2.016 & 1.672 \\
6 & 10 & 2.030 & 1.673 \\
\hline
\end{tabular}

(Sumber : Hasil Perhitungan, 2018)

\section{Berat Isi Basah}

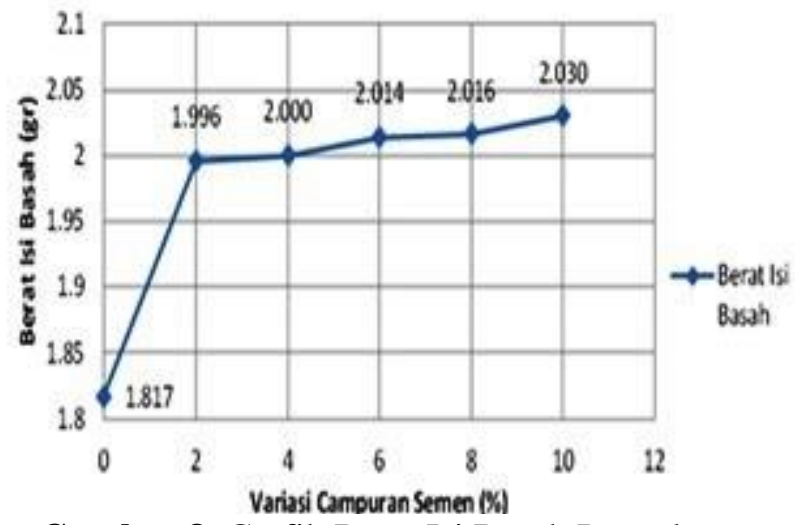

Gambar 8. Grafik Berat Isi Basah Pemadatan (compaction)

Dari Tabel hasil pengujian dan gambar diatas, menunjukan bahwa penambahan semen dapat meningkatkan berat isi basah tanah dari kondisi sebelum distabilisasi. Terlihat bahwa berat isi basah meningkat seiring bertambahnya semen, hai ini disebabkan semen mengisi rongga pori tanah, yang pada kondisi tanah asli rongga pori tersebut terisi oleh air dan udara. Akibat adanya semen dalam rongga pori tanah ini. Peningkatan jumlah partikel tanah berdampak peningkatan pada berat isi 
basahnya dibanding pada kondisi tanah aslinya, hali ini terlihat bahwa kepadatan maksimum terbesar terjadi pada penambahan kadar semen $10 \%$ sebesar $2,030 \mathrm{gr} / \mathrm{cm}^{3}$.

Pengujian Kuat Geser Langsung (Direct Shear Test)

Tabel 6. Hasil pengujian kuat geser dengan campuran semen

\begin{tabular}{ccccc}
\hline No. & $\begin{array}{c}\text { Kadar } \\
\text { Semen }(\%)\end{array}$ & $\begin{array}{c}\text { Teg. Geser } \\
\left(\mathrm{kg} / \mathrm{cm}^{2}\right)\end{array}$ & $\begin{array}{c}\mathrm{C} \\
\left(\mathrm{kg} / \mathrm{cm}^{2}\right)\end{array}$ & $\begin{array}{c}\text { Sudut } \\
\text { geser }\left({ }^{\circ}\right)\end{array}$ \\
\hline 1 & 0 & 0.252 & 0.029 & 28.81 \\
2 & 2 & 0.299 & 0.033 & 32.41 \\
3 & 4 & 0.339 & 0.052 & 35.18 \\
4 & 6 & 0.406 & 0.100 & 37.23 \\
5 & 8 & 0.452 & 0.131 & 38.30 \\
6 & 10 & 0.541 & 0.172 & 42.61 \\
\hline
\end{tabular}

(Sumber : Hasil Perhitungan, 2018)

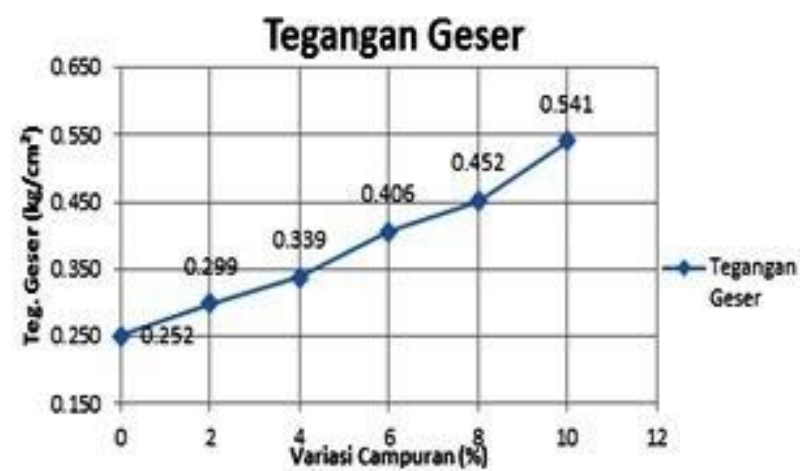

Gambar 9. Rekapitulasi hasil pengujian kuat geser tanah dengan semen

Dari gambar diatas terlihat bahwa dengan penambahan kadar semen mengalami kenaikan tegangan geser ini berarti bahwa semen mengisi rongga pori tanah dan peningkatan jumlah partikel padat pada tanah berdampak pada peningkatan tegangan geser pada setiap kadar pencampuran.

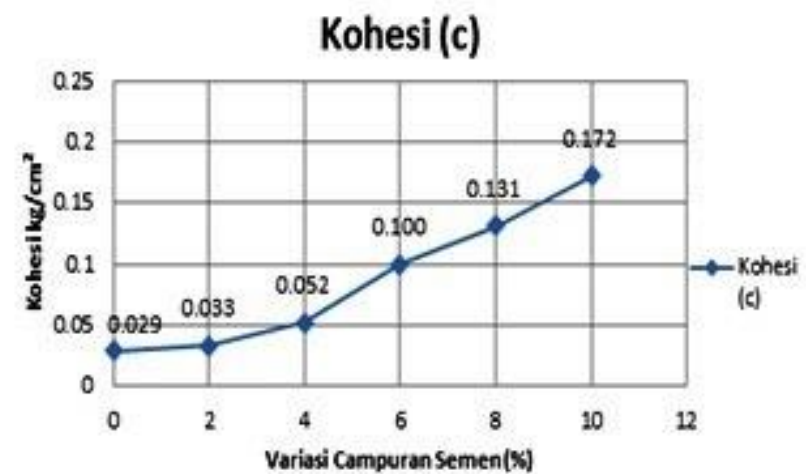

Gambar 10. Grafik perbandingan nilai kohesi variasi semen pengujian kuat geser

Dari gambar grafik hasil yang diperoleh bahwa semakin tinggi presentasi penambahan kadar semen maka semakin tinggi pula nilai kohesi ini berarti bahwa penggunaan semen dapat meningkatkan daya dukung tanah tersebut. Hal ini karena semen berfungsi sebagai material tang meribah sifat fisis dan mekanis secara kimiawi.

\section{Sudut Geser}

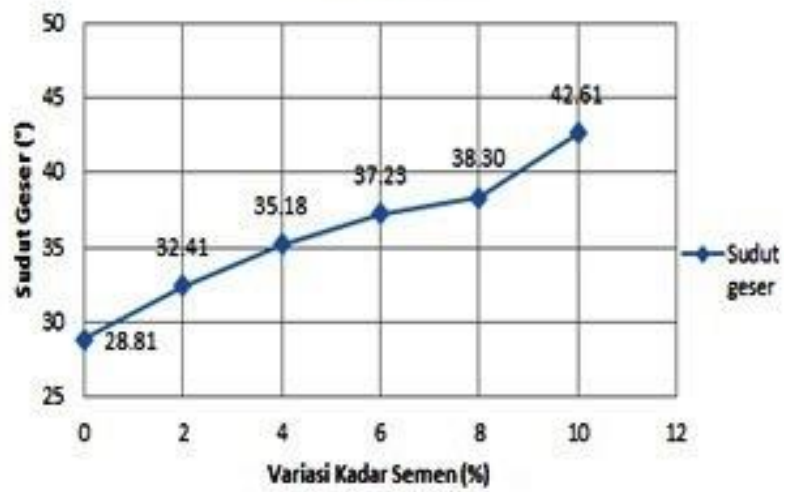

Gambar 11. Grafik perbandingan nilai sudut geser variasi semen pengujian kuat geser

Dari gambar grafik sudut geser diatas nilai sudut geser lebih tinggi di bandingkan dengan yang tidak dicampur dengan bahan stabilisasi. Dengan meningkatnya nilai kohesi dan sudut geser berarti bahwa meningkat pula kemampuan daya dukung tanah tersebut. Oleh karena itu, penggunaan semen dengan tanah yang mengandung lempung sangat efektif untuk meningkatkan daya dukung tanah tersebut terlihat dari kenaikan disetiap penambahan kadar semen.

\section{KESIMPULAN}

Kesimpulan yang diperoleh dari penelitian antara lain : (1)Berdasarkan pengujian fisis, menurut klasifikasi USCS tanah termaksud jenis $\mathrm{CH}$ yaitu tanah tak organik dengan plastisitas tinggi lempung gemuk. Begitupun pada klasifikasi AASHTO tanah termaksud golongan A-7-6 yaitu tanah lempung, yang berarti bahwa tanah asli di Jalan Makam Kelurahan Malason, Distrik Aimas, Kabupaten Sorong adalah tanah lempung. (2)Pengaruh penambahan semen telah meningkatkan nilai daya dukung tanah, penambahan campuran semen dapat meningkatkan nilai tegangan geser, kohesi dan sudut geser. Peningkatan nilai tegangan geser, kohesi dan sudut geser tertinggi pada campuran 10\% dengan waktu pemeraman 3 hari dengan nilai tegangan geser sebesar $0.541 \mathrm{~kg} / \mathrm{cm}^{2}$, kohesi sebesar 0,172 $\mathrm{kg} / \mathrm{cm}^{2}$ dan sudut geser sebesar $42,61^{\circ}$ yang berarti bahwa semen dapat digunakan sebagai material stabilitas tanah lempung dan kuat geser tanah lempung meningkat sejalan dengan penambahan kadar semen.

\section{REFERENSI}

Hardiyatmo. H. C, (2002). Mekanika Tanah 1 Edisi ke-tiga, Universitas Gadjah Mada, Yogyakarta. 
Hardiyatmo. H. C, (2010). Stabilitas Tanah Untuk Perkerasan Jalan, Universitas Gadjah Mada, Yogyakarta.

http://irwanto.info/gambaran-umum-kabupatensorong-provinsi-papua-barat/

http://ragilpandu.blogspot.co.id/2010/05/mekanikatanah-2-kuat-geser-tanah.html

Iqbal. (2017) Uji Eksperimental Pengaruh Variasi Kadar Semen Terhadap Nilai Cbr Tanah Lempung Yang Di Stabilisasi Dengan Semen. Universitas Muhammadiyah Sorong, Sorong.

SNI Revisi Dari 03 - 1964 - 1990 Ke 1964 - 2008 Metode Pengujian Berat Jenis Tanah

SNI Revisi Dari 03 - 1965 - 1990 Ke 1965 - 2008 Metode pengujian Kadar Air

SNI Revisi Dari 03 - 1966 - 1990 Ke 1966 - 2008 Metode Pengujian Batas plastis

SNI Revisi Dari 03 - 1967 - 1990 Ke 1967 - 2008 Metode Pengujian Batas Cair Dengan Alat Cassagrande

SNI Revisi Dari 03 - 2813 - 1992 Ke 2813 - 2008 Metode Pengujian Kuat Geser Langsung Tanah Terkonsolidasi dengan Drainase

SNI Revisi Dari 03 - 3423 - 1994 Ke 3423 - 2008 Metode pengujian Analisis Ukuran Butir Tanah Dengan Alat Hidrometer

Toyeb Muhammad, Puri Anas, Masrizal. (2017). Perilaku Kuat Geser Tanah Terstabilisasi Semen Untuk Subgrade Jalan. Univeritas Islam Riau, Pekanbaru.

Zardi Muhammad, Muklis. (2015). Pengaruh Pencampuran Semen Terhadap Kuat Geser Tanah Lempung Lampoh Keude. Universitas Abulyatama, Aceh Besar. 